\title{
Cellulose Morphology and Enzymatic Reactivity: A Modified Solute Exclusion Technique
}

\author{
F. M. Gama, J. A. Teixeira, and M. Mota* \\ Departmento de Engenharia Biológica, Universidade do Minho, Largo do \\ Paço, 4719 Braga Codex, Portugal
}

Received March 3, 1993/Accepted October 12, 1993

\begin{abstract}
An expeditious and accurate simplification of Stone and Scallan's solute exclusion technique was developed, thereby avoiding several sources of experimental error coupled with the determination of cellulose pore volume. Using this method, it is shown that cellulolytic enzymes do not enter into the micropores of five studied celluloses. These results suggest that hydrolysis occurs initially at the external surface of the fibers. This surface area was calculated with the help of adsorption isotherms of bovine serum albumin. The obtained values for the different samples agree with the microscopically observed cellulose morphology. The correlation obtained by several authors relating cellulose porosity and its digestibility is explained as a consequence of the lower crystallinity and easier fragmentation of the more porous celluloses during hydrolysis. (c) 1994 John Wiley \& Sons, Inc.
\end{abstract}

Key words: cellulose morphology - cellulase - pores • surface area

\section{INTRODUCTION}

Several potential industrial applications of cellulose are partially dependent on the effectiveness of the cellulolytic enzyme action. ${ }^{19}$ The natural cellulose properties-particle size, lignin level, crystallinity degree, porosity, accessible surface area, degree of polymerization-do not allow for a fast reaction, ${ }^{10}$ requiring, therefore, a pretreatment making these substrates more easily convertible to sugars. Which property should be considered as limiting in the hydrolysis mechanism has been so far a source of controversy. ${ }^{5}$

Two techniques are usually used to determine the cellulose surface area, based on the measurement of either the nitrogen adsorption ${ }^{7}$ or of the cellulose pore volume accessible to probes of different sizes-glucose, cellobiose, or polyethylene glycol (PEG). ${ }^{27,28}$

In the first case, the probe utilized is several orders of magnitude smaller than the cellulase molecule and the analyzed samples must be dried, therefore producing results which may be quite different from the real situation, in which celluloses are wet.

In the second technique (solute exclusion), the area corresponding to the cellulose pores can be evaluated, but the external surface (nonporous area) is considered negligible. In spite of this limitation, several authors obtained

\footnotetext{
* To whom all correspondence should be addressed.
}

good correlations between pore area values and cellulose digestibility, ${ }^{13,28,32,33}$ suggesting that this may be the key parameter in the cellulose hydrolysis reaction. The aim of this work is to verify whether this assertion is true, or otherwise, an indirect consequence of other hidden properties.

\section{MATERIALS AND METHODS}

\section{Enzyme}

The commercial cellulase enzyme from Trichoderma longibrachiatum, Multifect L-250, was obtained from the Finnish Sugar Co., Ltd., Helsinki, Finland.

\section{Cellulose}

Five kinds of cellulose were used: Sigmacell type 100 was purchased from Sigma Chemical Co.; Avicel PH101 was obtained from Honeywell and Stein, London, UK; commercial cotton, free of loose fibers, (Competência), was purchased from Bastos e Viegas, Porto, Portugal; amorphous cotton was prepared from the latter by solubilization in $85 \% \mathrm{H}_{3} \mathrm{PO}_{4}$, water reprecipitation and solvent drying according to Lee et al. ${ }^{16}$; and fibrous Whatman CF-11 cellulose was kindly provided by Dr. Nelson Lima.

\section{Enzymatic Digestion}

The reaction mixture, containing $15 \mathrm{mg}$ of cellulose, $1.5 \mathrm{~mL}$ of $0.1 M$ sodium 3,3'-dimethylglutarate buffer; $\mathrm{pH} 5.0$, and $0.5 \mathrm{~mL}$ of diluted enzyme (1:50), was placed for $6 \mathrm{~h}$ in a $50-\mathrm{mL}$ flask and incubated at $60^{\circ} \mathrm{C}, 120 \mathrm{rpm}$, in an orbital shaker. After $3 \mathrm{~mL}$ of water addition, the reaction medium was centrifuged $(3000 \mathrm{rpm}, 3 \mathrm{~min})$, and the solubilized sugars were measured by HPLC as described previously. ${ }^{9}$

\section{Probes}

Glucose, cellobiose, and 10 different PEG with $M_{r}$ between 200 and 10,000, corresponding to molecule diameters between 13 and $95 \AA$, were used in the solute exclusion experiments. ${ }^{17}$ 


\section{Pore Volume Distribution (Solute Exclusion Technique)}

All the assays were repeated four times. Cellulose powder $(1000 \mathrm{mg}$ ) was placed in contact with $11 \mathrm{~mL}$ of the probe solution $(0.7 \% \mathrm{w} / \mathrm{v})$. The blends were mixed for $5 \mathrm{~h}$ in an orbital shaker. Cellulose swelling and motion of the probe molecules into the pores occurred simultaneously, thereby reducing the experimentation time.

During the swelling process, probe solutions became more concentrated. The increase in concentration is proportional to the pore volume inaccessible to the probe but accessible to water.

After a 5-h swelling period, suspensions were transferred to test tubes and allowed to settle down for $1 \mathrm{~h}$. The supernatants were then centrifuged at $5000 \mathrm{rpm}$ for $10 \mathrm{~min}$. The settling step is important to avoid cellulose packing during centrifugation, which would give rise to water removal from the pores. The concentration of the probe solutions was determined refractometrically, ${ }^{17}$ using HPLC.

Considering:

$C_{f}=$ final probe concentration in supernatant after contact with cellulose.

$M_{p}=$ initial probe weight in the probe solution.

$W_{1}=$ initial water volume in the probe solution.

$W_{2}=$ volume of adsorbed water to cellulose, prior to contact with the probe solution, determined by dry weight measurement after overnight drying of the cellulose at $100^{\circ} \mathrm{C}$ (assuming density of $1 \mathrm{~g} / \mathrm{L}$ ).

$V_{i}=$ pore volume accessible to water but inaccessible to probe molecules.

$V_{a}=$ pore volume accessible to probe molecules.

$V_{\max }=$ maximum $V_{i}$, determined as the mean value of the $V_{i}$ 's for the probes with $M_{r}$ between 3350 and 10,000 .

the following mass balance may be defined:

$$
C_{f}=M_{p} /\left(W_{1}+W_{2}-V_{i}\right)
$$

Then, the pore volume accessible to probes can be calculated according to the equation:

$$
V_{a}=V_{\max }-\left(W_{1}+W_{2}\right)+\left(M_{p} / C_{f}\right)
$$

Combining Eqs. (1) and (2):

$$
\begin{aligned}
V_{a}=V_{\max }- & \left(W_{1}+W_{2}\right) \\
& +\left(W_{1}+W_{2}-V_{i}\right)=V_{\max }-V_{i}
\end{aligned}
$$

\section{Adsorption Experiments}

Adsorption isotherms of bovine serum albumin (BSA) on cellulose were obtained using the following procedure: One milliliter of BSA solution in $50 \mathrm{mM}$ phosphate buffer, $\mathrm{pH} 5.0$, with initial concentrations between $5.0 \mu \mathrm{g} / \mathrm{mL}$ and $2.5 \mathrm{mg} / \mathrm{mL}$, was mixed with $50 \mathrm{mg}$ cellulose in a 2-mL Eppendorf tube. A water volume corresponding to the inaccessible pore volume of each cellulose sample
(20 to $70 \mu \mathrm{L}$ ), as determined by the solute exclusion technique, was added to the mixture. The suspension was incubated for $16 \mathrm{~h}$ in an orbital shaker $\left(100 \mathrm{rpm}, 20^{\circ} \mathrm{C}\right)$. Complete resuspension was executed manually several times. The long equilibration period may be necessary to allow for a more efficient packing and an increase in the adsorbed amount to occur. During this period, conformational changes lead to an increased surface interaction (initial adsorption requires only 100 to $200 \AA$, irrespective of the protein size). ${ }^{1}$ The samples were then allowed to sediment for $1 \mathrm{~h}$, to avoid interference of the centrifugation step on the adsorption equilibrium. ${ }^{11}$ The supernatant was then centrifuged (5000 rpm, $5 \mathrm{~min}$ ), and analyzed for protein concentration by the method of Bradford, using BSA solutions as standard. Assays were executed in triplicate.

\section{Total Surface Area Determination}

The surface area was determined by measuring the $\mathrm{N}_{2}$ adsorption. A Quantacrome apparatus was utilized. Nitrogen was used as adsorbate gas. Desorptions at three different nitrogen partial pressures were performed in order to plot a three-point BET graph. ${ }^{7}$ The cellulose samples were degassed previously at $140^{\circ} \mathrm{C}$ for $8 \mathrm{~h}$.

\section{Crystallinity Measurements}

Crystallinity was measured using a powder diffractometer, type PW1710 BASED, operated at a $40-\mathrm{kV}$ tube voltage and a $30-\mathrm{mA}$ tube current. The samples were scanned for a range of $2 \theta$ from $10^{\circ}$ to $30^{\circ}$. The crystallinity index (CrI) was calculated as described by Fan et al. ${ }^{7}$

\section{Microscopy}

Scanning electron microscopy was executed on a Jeol JSM35C apparatus operated at $25 \mathrm{kV}$.

\section{RESULTS}

\section{Pore Volume Determination}

In the original method developed by Stone and Scallan, ${ }^{27,28}$ the cellulose is previously swollen with water, and then a certain volume of probe solution is added to the drained sample. After an incubation time, the dilution is measured. The water content of the cellulose samples is variable, ${ }^{33}$ thereby becoming one source of error. This is why it takes some time to get consistent and reproducible data. ${ }^{13}$ Lin et al. ${ }^{17}$ obtained an average relative standard deviation for total inaccessible pore volumes of $11.2 \%$. Sample preparation, including washing and filtering, add significant deviation in these experiments. The standard deviation associated with the modified method was only $0.9 \%$. Furthermore, the use of centrifugation instead of filtration has improved the removal of fine cellulose particles, which are 
a source of interference during the refractometric measurements. Hence, the described procedure is not only more expeditious than the original one, but also more rigorous, and it can be applied irrespective of the cellulose particle size distribution. ${ }^{21}$ The obtained fiber saturation points (pore volume accessible to the water molecule) between 0.4 to $1.4 \mathrm{~mL} / \mathrm{g}$ (Fig. 1) are within the range of results reported in literature. ${ }^{13,21,27,32,33}$

\section{Adsorption Isotherms-Surface Area Determination}

The Langmuir plots of the obtained adsorption data are displayed in Figure $2 \mathrm{a}$ and $\mathrm{b}$. Correlation coefficients above 99.7\% were found applying a linear regression to the Ruzic plots $^{24}$ (Fig. 2c):

$$
\left(P / P_{\mathrm{ads}}\right)=(P+1 / K) / P_{\mathrm{ads}, m}
$$

where $P$ is the free protein concentration $(\mathrm{mg} / \mathrm{mL}), P_{\text {ads }}$ is the adsorbed protein ( $\mathrm{mg}$ adsorbed protein $/ \mathrm{g}$ cellulose), $P_{\text {ads }, m}$ is the maximal adsorbed protein ( $\mathrm{mg}$ adsorbed protein/g cellulose), and $K$ is the adsorption equilibrium constant $(\mathrm{g} / \mathrm{mL})$.

The determined $\boldsymbol{P}_{\mathrm{ads}, \boldsymbol{m}}$ were utilized in the calculation of the cellulose surface area. The BSA molecule is known to be ellipsoidal in solution, measuring $111.6 \times 27 \times 27 \AA$, and was shown to adsorb "end-on" to silica surfaces. ${ }^{8}$ Then, provided that this protein does not follow extensive configurational rearrangement upon adsorption, each molecule should cover a circular area of cellulose with a radius of approximately $27 \AA$.
As it may be seen in Table I, the areas determined by this technique are small as compared with the areas calculated using other techniques. However, the different techniques actually measure distinct structural components of the cellulose surface (Fig. 3).

From the results obtained by the solute exclusion technique, only the pore surface area can be calculated by assuming a defined pore geometry and a defined penetration factor $^{20}$ (relationship between the diameter of the polymer molecule and the diameter of the pore to be penetrated). These assumptions may be quite different from the real situation.

The nitrogen adsorption technique gives a measure of the total surface area of the dry solid, i.e., pores and external surface area. Residual water may occlude a significant amount of this surface. ${ }^{14}$ As may be seen in Figure 3, a larger porosity will imply a larger total surface area. This is confirmed by comparing the porosity values in Table II with the surface values obtained by this technique in Table I.

The cellulase adsorption isotherms, given by some authors, are obtained after an equilibration period of about 30 to $60 \mathrm{~min}$. Because one of the early events observed during the enzymatic hydrolysis is the cellulose fragmentation, ${ }^{31}$ the amount of adsorbed cellulase is quite probably affected by the increasing accessible surface area. On the other hand, Nieves et al. ${ }^{22}$ showed that cellulases adsorb on the cellulose surface as aggregated particles. In such a case, protein multilayers may exist on saturated cellulose, hence, the surface area is overestimated.

The above discussion shows that the assessment of true surface areas is questionable. As shown here (Fig. 2),

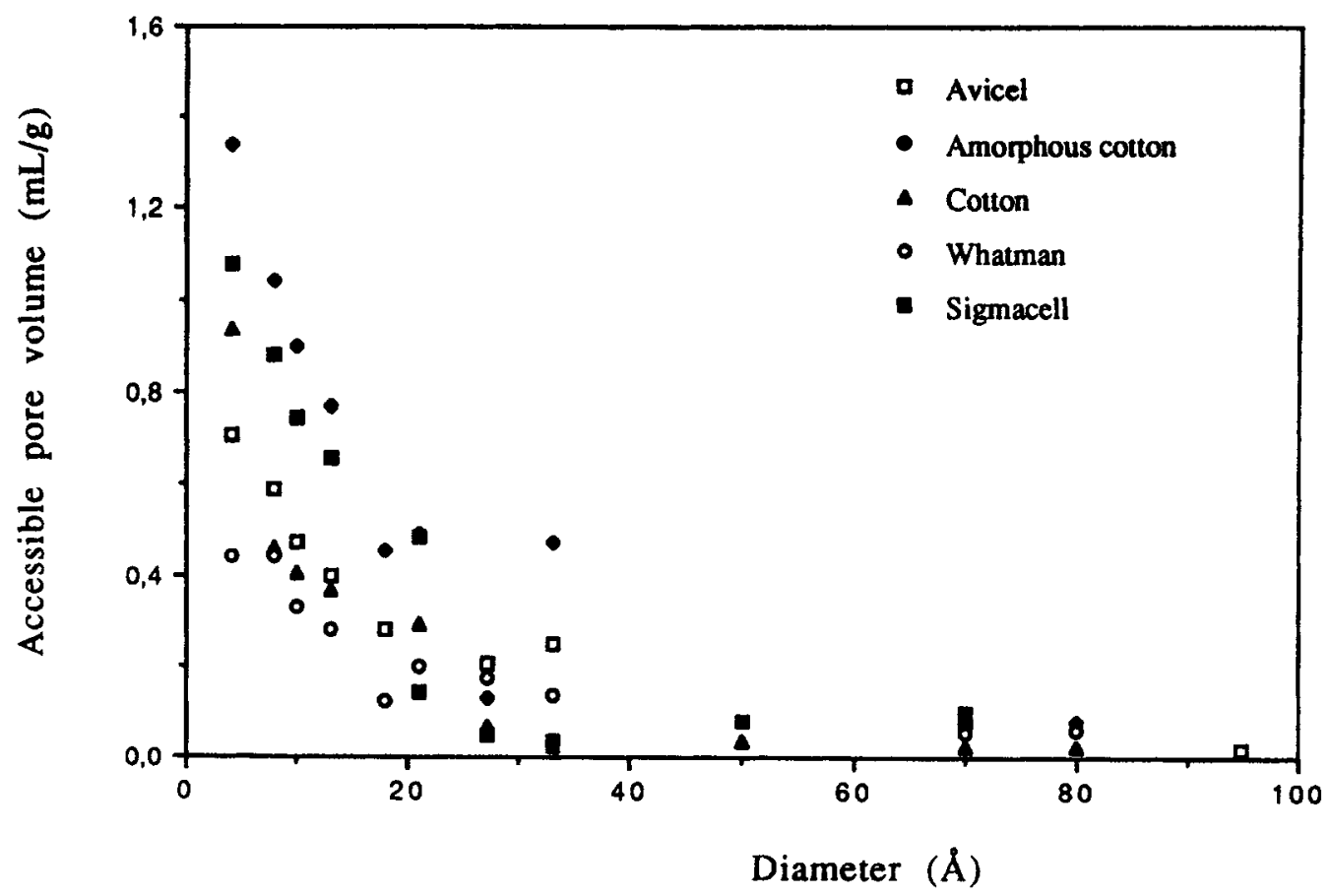

Figure 1. Pore volume distribution of celluloses. 

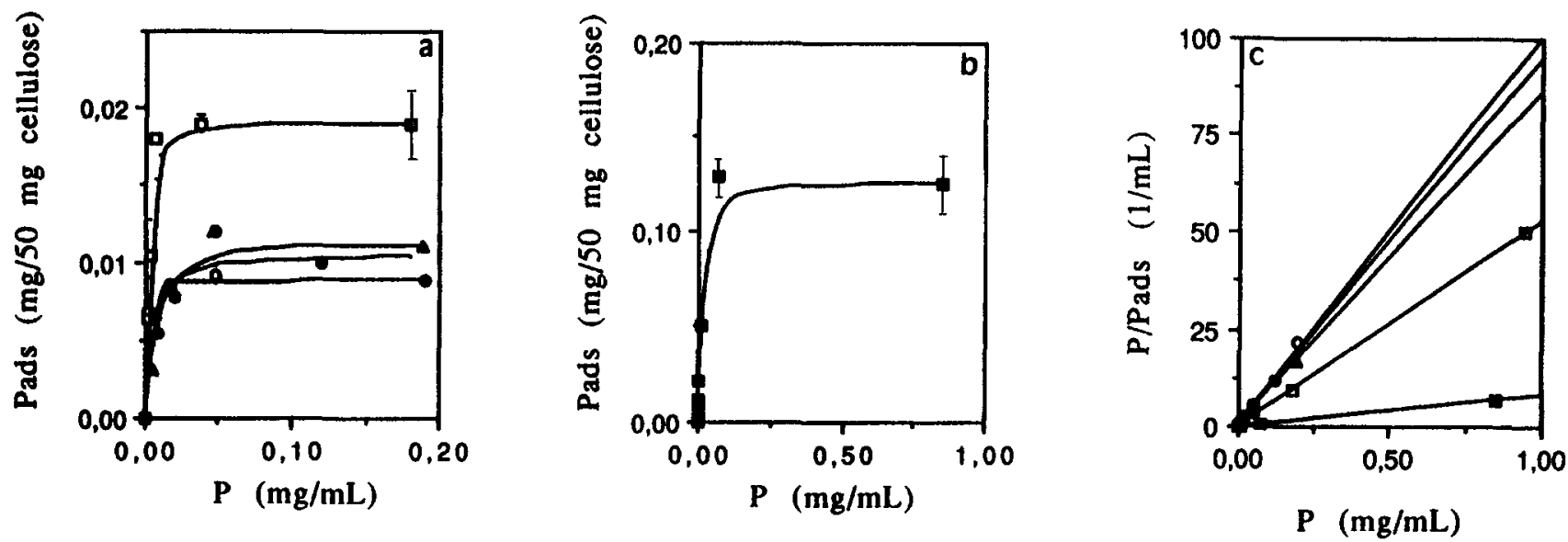

Figure 2. (a) and (b) Langmuir plots of the BSA adsorption data: ( $\square$ ) Avicel; ( $\square$ ) Sigmacell; (A) cotton; $(O)$ amorphous cotton; $(O)$ Whatman. The confidence limits of the $P_{\text {ads, } m}$ values of the celluloses Avicel and Sigmacell are shown. (c) Ruzic representation of the adsorption data.

the adsorption isotherms of BSA-a molecule with a similar size of cellulases - can be obtained consistently, without the drawbacks of cellulase adsorption. Therefore, this technique gives a more realistic determination of the accessible surface area.

\section{Cellulose Characterization and Enzymatic Reactivity}

All celluloses except amorphous cotton produced a diffraction pattern similar to type I celluloses, as judged from $2 \theta$ at $16^{\circ}$ and $22.5^{\circ} .{ }^{15}$ After enzymatic treatment, the amorphous cotton showed a similar diffraction profile (Fig. 4), suggesting that the phosphoric acid treatment was ineffective in the inner part of the fibers.
Physical parameters of the celluloses studied in this work (see Fig. 5), as well as their enzymatic digestibility, are summarized on Table II. A relationship with a correlation coefficient of $-88.3 \%$ can be observed between the crystallinity index and the fiber saturation point of cellulose. In a way, porosity measurements reflect the molecular organization at the elementary fibers level. This correlation was first reported by Ryu et al., ${ }^{25}$ and points out the interdependence of the cellulose physical properties. The relatively low value of this correlation coefficient may reflect the existence of different porosities within and between the microfibrils and lamella (supramolecular organization level). This can be a result of different hemicellulose contents, as is possibly the case in the natural celluloses analyzed by Grethlein. ${ }^{12}$ The relations between porosity and reactivity, reported by many

Table I. Cellulose surface area as determined by different techniques.

\begin{tabular}{|c|c|c|c|c|}
\hline Cellulose & Technique & $\begin{array}{c}\text { Surface } \\
\text { area }^{a}\left(m^{2} / g\right)\end{array}$ & $\begin{array}{l}P_{\text {ads }, m} \\
(\mathrm{mg} / \mathrm{g})\end{array}$ & Ref. \\
\hline Avicel PH-101 & BSA ads. & $0.080 \pm 0.001$ & 0.38 & This work \\
\hline Sigmacell 100 & $"$ & $0.61 \pm 0.06$ & 2.90 & $"$ \\
\hline Whatman CF-11 & $"$ & $0.040 \pm 0.001$ & 0.19 & $"$ \\
\hline Crystalline cotton & $"$ & $0.040 \pm 0.001$ & 0.21 & $"$ \\
\hline Amorphous cotton & $"$ & $0.052 \pm 0.004$ & 0.23 & $"$ \\
\hline Avicel PH-101 & Cellulase ads. & 2.5 & 9 & 26 \\
\hline " & " & 19 & 69 & $"$ \\
\hline Cotton & $"$ & & 12 & 16 \\
\hline Avicel PH-102 & $"$ & & 64 & $"$ \\
\hline Defibered pulp & Solute excl. & 2.56 & & 29 \\
\hline Acid swollen cotton & " & $10-100$ & & 28 \\
\hline Solka flok BW-300 & $"$ & 0 & & 20 \\
\hline Sigmacell 100 & $\mathrm{~N}_{2}$ ads. & 3.00 & & This work \\
\hline Avicel PH-101 & " & 2.07 & & " \\
\hline Whatman CF-11 & $"$ & 0.69 & & $"$ \\
\hline
\end{tabular}




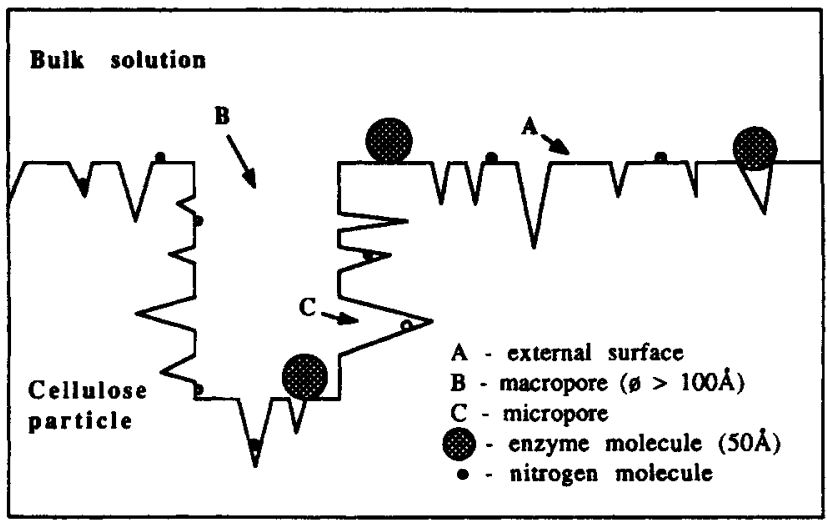

Figure 3. Schematic representation of the structural features of the cellulose particle surface, showing the influence of probe size on the determination of total and external surface area.

authors, can thus partially imply a reverse relation between crystallinity and digestibility.

For example, Whatman cellulose has the lowest porosity and the highest crystallinity, implying minimal digestibility. On the contrary, amorphous cotton and Sigmacell have the reverse properties, presenting high digestibility.

\section{DISCUSSION}

The pores of the tested celluloses were almost impermeable to probes with a diameter above $50 \AA$ (Fig. 1). Similar results were reported for untreated celluloses, as well as for $\mathrm{NaOH}$ (cellulose swelling agent) or FeTNa (iron sodium tartarate-intercalates between cellulose microfibrils) treated substrates. ${ }^{2,3,18}$. Considering that cellulolytic enzymes have an average diameter of $59 \AA, 29$ it is rather questionable that cellulases are acting inside the cellulose pores.

Caulfield and Moore ${ }^{4}$ suggested that the overall increase in digestibility following cellulose pretreatments can be the result of decreased particle size. Cellulose pretreatments ineffective on microporosity produced some fragmentation and increased digestibility. The external surface area may then be an important reaction parameter. ${ }^{23}$

Table II. Physical characterization and enzymatic digestibility of celluloses.

\begin{tabular}{lcccc}
\hline \multicolumn{1}{c}{ Cellulose } & $\begin{array}{c}\text { Surface } \\
\text { area } \\
\left(\mathrm{m}^{2} / \mathrm{g}\right)\end{array}$ & $\begin{array}{c}\mathrm{CrI}^{\mathrm{a}} \\
(\%)\end{array}$ & $\begin{array}{c}\text { Porosity } \\
(\mathrm{mL} / \mathrm{g})\end{array}$ & $\begin{array}{c}\text { Digestibility } \\
(\%)\end{array}$ \\
\hline Avicel & 0.080 & 81.3 & 0.70 & 19.9 \\
Sigmacell & 0.61 & 76.6 & 1.09 & 24.9 \\
Whatman & 0.040 & 84.8 & 0.42 & 5.6 \\
Crystalline cotton & 0.040 & 82.2 & 0.93 & 6.7 \\
Amorphous cotton & 0.052 & 64.5 & 1.35 & 74.0 \\
\hline
\end{tabular}

${ }^{a} \mathrm{CrI}=$ crystallinity index.

${ }^{\mathrm{b}}$ Porosity values correspond to celluloses fiber saturation points.

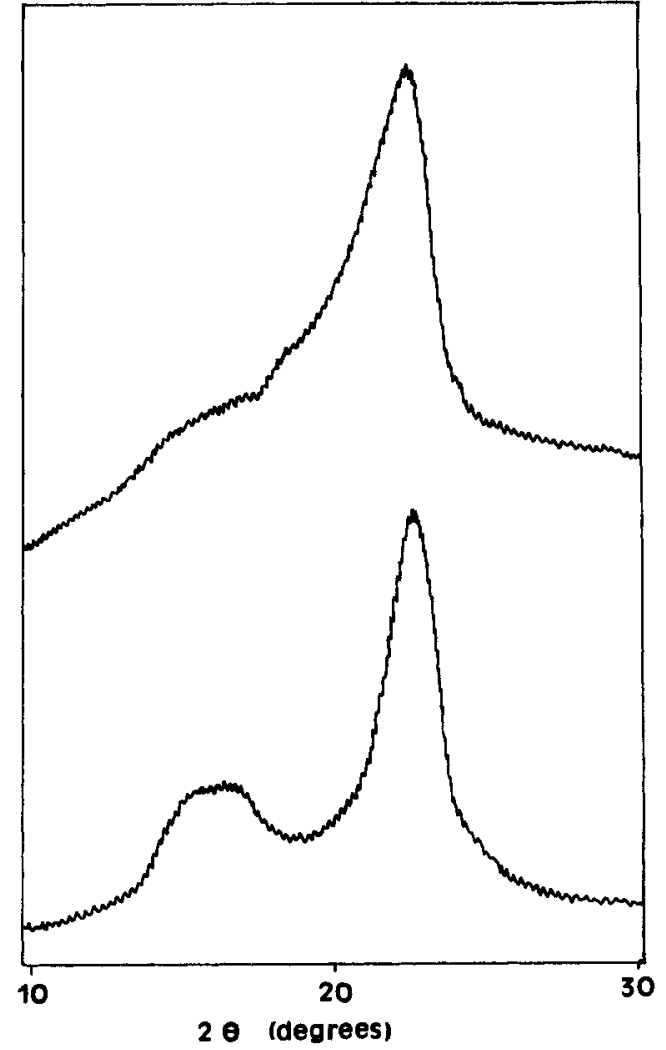

Figure 4. X-ray diffractograms of amorphous cellulose before (above) and after (below) enzymatic treatment.

The BSA adsorption results suggest that a $55-\AA$ diameter molecule does not penetrate cellulose pores, as predicted by the solute exclusion technique. Indeed, the relative order of the obtained surface area values reflects the size of the cellulose particles (Fig. 5a to 5e): the smaller the particles, the higher the surface areas. Although amorphous cotton has a fiber saturation point $50 \%$ higher than crystalline cotton, it displays a similar accessible surface area to the BSA molecule. This demonstrates that the external surface represents a major portion of the enzyme's accessible surface. However, there are celluloses with a considerable available pore volume. ${ }^{12,28,32,33}$ These authors obtained good correlations between the pore volume accessible to molecules with sizes of about $40 \AA$ and the cellulose digestibility, claiming that the pore surface area is the limiting parameter in the hydrolysis reaction. From our point of view, this hypothesis does not fully explain the experimental evidence.

First, the synergistic action between endo- and exo-type enzymes would demand the simultaneous or consecutive penetration of these proteins into the pores, as well as a correct stereochemical orientation. Because every cellulase complex is formed by several proteins with a wide range of molecular weights $(30,000$ to 70,000$),{ }^{6}$ exclusion phenomena may occur in the pores, partially avoiding synergism. ${ }^{29}$ Therefore, synergism should occur mainly at 


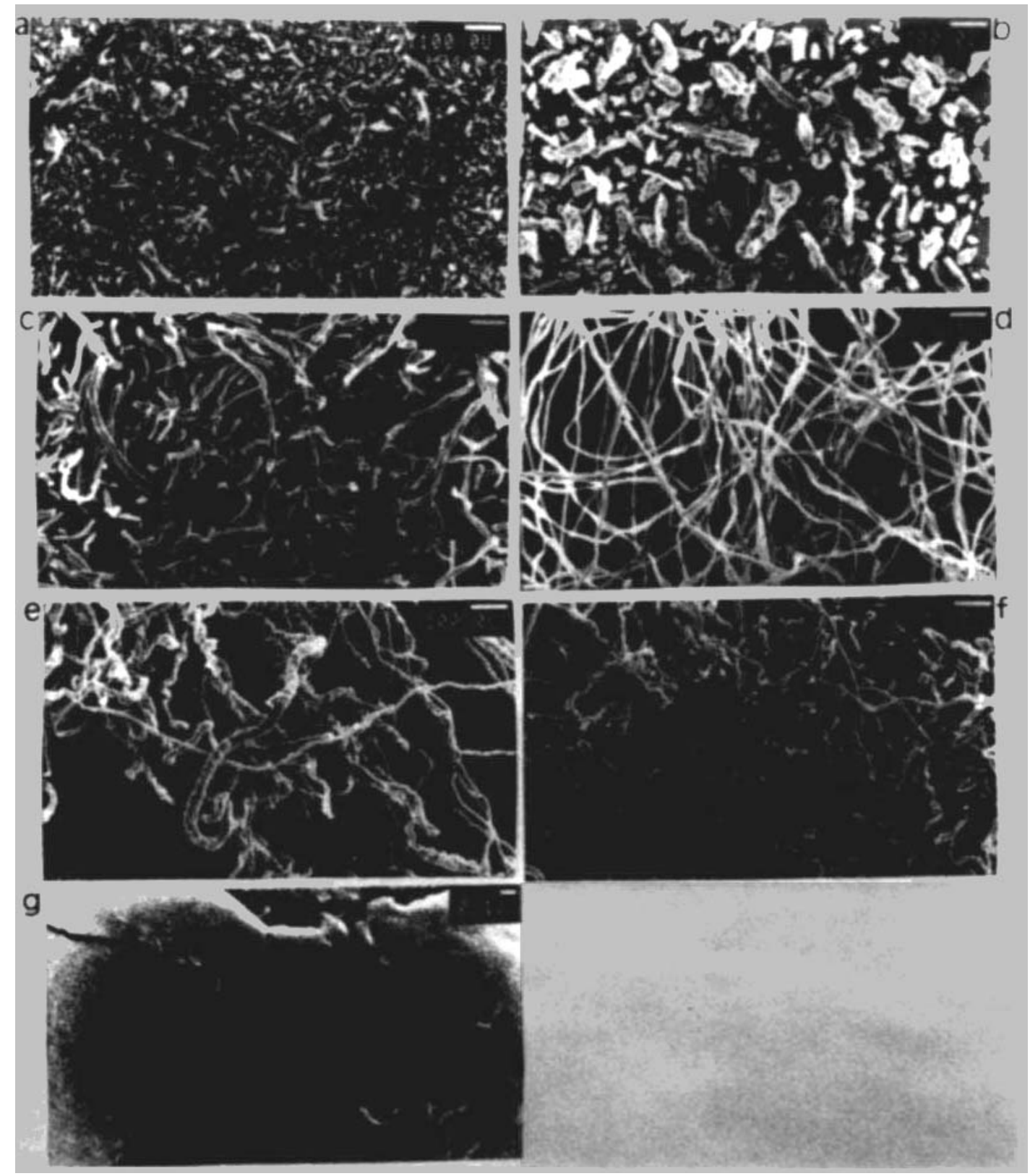

Figure 5. Photomicrographs of the studied celluloses: (a) Sigmacell; (b) Avicel; (c) Whatman; (d) cotton; (e) amorphous cotton; (f) amorphous cotton after 0.5 -h enzymatic digestion, revealing the fragmentation on the beginning of the reaction; and (g) Sigmacell surface-exhibiting macropores.

the exterior surface level and inside the macropores or irregularities, as observed in Fig. $5 \mathrm{~g}$.

Product concentration inside the pores can also be a critical aspect. With the pores partially filled with protein, sugar diffusion to the bulk solution is somehow impaired, thereby increasing inhibition. Tanaka et al. ${ }^{30}$ suggested that some cellulases diffuse very slowly into the narrow spaces between the microfibrils, and that these exhibit a lower catalytic action than that of the proteins adsorbed onto the surface of the fibers.

The main conclusion of this work is that the external surface area, including the macropores, represents a measure of the effective contact area between cellulose and enzymes in the beginning of the reaction. However, this contact surface is not, in itself, relevant to cellulose reactivity. This is because fragmentation can greatly increase the accessible surface area, depending on the porosity and cellulose particle size. This seems to be the case with amorphous cotton: having a great porosity (essentially inaccessible to the enzyme molecules), it becomes fragmented into many small fibers in the beginning of the reaction (Fig. 5f). The resulting higher amorphous accessible surface area enables a faster reaction. In fact, in spite of having a tenfold smaller external surface area than Sigmacell, the extent of amorphous cotton hydrolysis is three times larger.

The authors acknowledge Dr. Nelson Lima for his fruitful conversation and contributions to the present work. 


\section{References}

1. Andrade, J.D. 1985. Principles of protein adsorption, pp. 58-66. In: J.D. Andrade (ed.), Surface and interfacial aspects of biomedical polymers (vol. 2). Plenum Press, New York.

2. Bertoniere, N. R. 1989. Pore structure analysis of cotton cellulose via gel permeation chromatography, pp. 99-104. In: J.F. Kennedy, G. O. Phillips, and P. A. Williams (eds.), Cellulose-structural and functional aspects. Ellis Horwood, Chichester, UK.

3. Bertoniere, N. R., King, W.D. 1989. Effect of scouring/bleaching, caustic mercerization, and liquid ammonia treatment on the pore structure of cotton textile fibres. Text. Res. J. 59: 114-121.

4. Caulfield, D. F., Moore, W. E. 1974. Effect of varying crystallinity of cellulose on enzymic hydrolysis. Wood Sci. 6: 375-379.

5. Coughlan, M.P. 1992. Enzymic hydrolysis of cellulose: an overview. Biores. Technol. 39: 107-115.

6. Enari, T.-M., Niku-Paavola, M.-L. 1987. Enzymatic hydrolysis of cellulose: Is the current theory of the mechanisms of hydrolysis valid? CRC Crit. Rev. Biotechnol. 5: 67-87.

7. Fan, L.T., Lee, Y.-H., Beardmore, D. H. 1980. Mechanism of the enzymatic hydrolysis of cellulose: effects of major structural features of cellulose on enzymatic hydrolysis. Biotechnol. Bioeng. 22: 177-199.

8. Fitzpatrick, H., Luckham, P. F., Eriksen, S., Hammond, K. 1992. Use of Xray photoelectron spectroscopy to study protein adsorption to mica surfaces. J. Coll. Interf. Sci. 149: 1-9.

9. Gama, F. M., Faro, C. J., Teixeira, J. A., Mota, M. 1993. New methodology for the characterization of endoglucanase activity and its application on the Trichoderma longibrachiatum celluloytic complex. Enz. Microb. Technol. 15: 57-61

10. Gharpuray, M.M., Lee, Y.-H., Fan, L.T. 1983. Structural modification of lignocellulosics by pretreatments to enhance enzymatic hydrolysis. Biotechnol. Bioeng. 25: 157-172.

11. Gonçalves, M. L. S., Sigg, L., Stumm, W. 1985. Voltammetric methods for distinguishing between dissolved and particulate metal ion concentrations in the presence of hydrous oxides. A case study of lead (II). Environ. Sci. Technol. 19: 141-146.

12. Grethlein, H.E. 1985. The effect of pore size distribution on the rate of enzymatic hydrolysis of cellulosic substrates. Bio/Technol. 3: $155-160$.

13. Grethlein, H.E., Allen, D.C., Converse, A. O. 1984. A comparative study of the enzymatic hydrolysis of acid-pretreated white pine and mixed hardwood. Biotechnol. Bioeng. 26: 1498-1505.

14. Hollenbeck, R.G., Peck, G.E., Kildsig, D. O. 1978. Application of immersional calorimetry to investigation of solid-liquid interactions: microcrystalline cellulose-water system. J. Pharm. Sci. 67: 1699-1706.

15. Isogai, A., Usuda, M., Kato, T., Uryu, T., Attala, R. H. 1989. Solid-state CP/MAS ${ }^{13} \mathrm{C}$ NMR study of cellulose polymorphs. Macromolecules 22: 3268-3172.

16. Lee, S. B., Shin, H. S., Ryu, D. D. Y., Mandels, M. 1982. Adsorption of cellulase on cellulose: effect of physicochemical properties of cellulose on adsorption and rate of hydrolysis. Biotechnol. Bioeng. 24: $2137-2153$.

17. Lin, J. K., Ladisch, M. R., Patterson, J. A., Noller, C. H. 1987. Determining pore size distribution in wet cellulose by measuring solute exclusion using a differential refractometer. Biotechnol. Bioeng. 29: 976-981.

18. Lin, K.W., Ladisch, M. R., Voloch, M., Patterson, J. A., Noller, C.H. 1985. Effect of pretreatments and fermentation on pore size in cellulosic materials. Biotechnol. Bioeng. 27: 1427-1433.

19. Mandels, M. 1982. Cellulases, pp. 35-78. In: G. Tsao (ed.), Annual report of fermentation proceedings. Vol. 5. Academic Press, New York.

20. Nelson, R., Oliver, D. W. 1971. Study of cellulose structure and its relation to reactivity. J. Polym. Sci. C 36: 305-320.

21. Neuman, R.P., Walker, L.P. 1992. Solute exclusion from cellulose in packed columns: experimental investigation and pore volume measurements. Biotechnol. Bioeng. 40: 218-225.

22. Nieves, R. A., Ellis, R.P., Todd, R. J., Johnson, T. J. A., Grohmann, K., Himmel, M.E. 1991. Visualization of Trichoderma reesei cellobiohydrolase I and endoglucanase I on aspen cellulose by using monoclonal antibody-colloidal gold conjugates. Appl. Environ. Microbiol. 57: 3163-3170.

23. Reese, E. T., Segal, L., Tripp, V.W. 1957. The effect of cellulase on the degree of polymerisation of cellulose and hydrocellulose. Text. Res. J. 27: 626-632.

24. Ruzic, I. 1982. Theoretical aspects of the direct titration of natural waters and its information yield for trace metal speciation. Anal. Chim. Acta 140: 99-113.

25. Ryu, D. D. Y., Lee, S. B., Tassinari, T., Macy, C. 1982. Effect of compression milling on cellulose structure and on enzymatic hydrolysis kinetics. Biotechnol. Bioeng. 24: 1047-1067.

26. Stahlberg, J., Gunnar, J., Pettersson, J. 1991. A new model for enzymatic hydrolysis of cellulose based on the two-domain structure of cellobiohydrolase I. Bio/Technol. 9: 266-290.

27. Stone, J. E., Scallan, A. M. 1968. A structural model for the cell wall of water-swollen wood pulp fibres based on their accessibility to macromolecules. Cell. Chem. Technol 2: 343-358.

28. Stone, J. E., Scallan, A. M., Donefer, E., Ahlgren, E. 1969. Digestibility as a simple function of a molecule of similar size to a cellulase enzyme. Adv. Chem. Ser. 95: 219-241.

29. Tanaka, M., Ikesaka, M., Matsuno, R., Converse, A. O. 1988. Effect of pore size in substrate and diffusion of enzyme on hydrolysis of cellulosic materials with cellulases. Biotechnol. Bioeng. 32: 698-706.

30. Tanaka, M., Nakamura, H., Taniguchi, M., Morita, T., Matsuno, R., Kamikubo, T. 1986. Elucidation of adsorption processes of cellulases during hydrolysis of crystalline cellulose. Appl. Microbiol. Biotechnol. 23: 293-268.

31. Walker, L. P., Wilson, D. B., Irwin, D. C. 1990. Measuring fragmentation of cellulose by Thermonospora fusca cellulase. Enz. Microb. Technol. 12: 378-386.

32. Weimer, P. J., Weston, W.M. 1985. Relationship between the fine structure of native cellulose and cellulose degradability by the cellulase complexes of Trichoderma reesei and Clostridium thermocellum. Biotechnol. Bioeng. 27: 1540-1547.

33. Wong, K. Y., Deverell, K. F., Mackie, K. L., Clark, T. A., Donaldson, L.A. 1988. The relationship between fibre porosity and cellulose digestibility in steam-exploded Pinus radiata. Biotechnol. Bioeng. 31: $447-456$. 